\title{
3 Research Suare \\ Extraction of Alternative Activities to Diversify the Medical, Dentistry, and Pharmacy Student's Thesis
}

Mahla Salajegheh

Kerman University of Medical Sciences

Somayeh Noori Hekmat ( $\nabla$ snhekmat@gmail.com )

Kerman University of Medical Sciences

Reza Malekpour-afshar

Kerman University of Medical Sciences

\section{Research Article}

Keywords: Dissertation, Alternative, Medicine, Dentistry, Pharmacy

Posted Date: September 16th, 2021

DOI: https://doi.org/10.21203/rs.3.rs-731529/v1

License: (1) This work is licensed under a Creative Commons Attribution 4.0 International License.

Read Full License 


\section{Abstract}

Background: Nowadays, the correspondence of medical, dentistry, and pharmacy student's thesis with health issues and challenges of the society is a crucial concern of universities of medical sciences. Because the product-oriented thesis can significantly affect students' scientific and practical abilities and lead to the provision of more efficient services to society. The present study aimed to extract alternative activities to diversify medical, dentistry, and pharmacy student's thesis in Kerman University of medical Sciences.

Methods: This study was a descriptive cross-sectional study using the sequential exploratory design and conducted in the Education Development Center of Kerman University of Medical Sciences between February and June 2021. The qualitative phase aimed to extract alternative activities to diversify medical, dentistry, and pharmacy student's thesis in three steps (literature review, scoring the extracted alternative activities, and implementing expert panel). The quantitative phase aimed to assess the extracted alternative activities to diversify medical, dentistry, and pharmacy student's thesis.

Results: According to the results of the two phases, 18 alternative activities were identified and categorized into five domains of individual development, research, education, healthcare, and social services.

Conclusions: The gap between what we know and what is seen in practice in medical, dentistry, and pharmacy student's thesis is quite apparent. According to research, it is always recommended that knowledge manifest itself in the society; however, the present study aimed to extract activities to replace student's dissertations so that they may turn into practice and contribute to social services.

\section{Background}

Without any question, in the present day, countries' development and progress are based on science (1). Research and production of science are the most prominent factors of each country's economic, social, cultural, industrial, and political growth. Universities are unquestionably the most important organizations with the significant effect on research and production (2). Research in universities of medical sciences has a greater importance due to their crucial consequences in different aspects of the society's health (3). According to Gouda et al (2016), most students and professors of medical sciences considered basic or clinical research as useful instrument to prepare students for the practice of medicine (4). In this regard, medicine, dentistry, and pharmacy thesis are the requirements of universities of medical sciences. This leads to the inclusion of outstanding individuals whose scientific competence has been approved by the university based on a scientific dissertation to the cycle of science production, health, and medicine (5).

Among educational and research activities in medicine, dentistry, and pharmacy programs, dissertations play a significant role. A dissertation is an important resource for science production because it combines education and research (6). Moreover, as a representative of research for a medicine, dentistry, and pharmacy educational program, dissertations can be considered science production (7). In other words, 
these valuable resources are benchmarks that, students can use to complete their educational activities and develop their field of study (8).

The results of months, even years, of students' study and research and their interaction with supervisors has great significance, and it is expected that medicine, dentistry, and pharmacy dissertations not only discuss the health issues of the society but also make an effort to deal with challenges facing healthcare services.

However, these valuable goals of dissertations have lost their standing in Iran and in many developed societies (9). In addition, despite the considerable time, energy, and budget used in conducting dissertations, the results are limited to libraries or papers. This leads to a condition in which no new knowledge is added, and a significant amount of time and money is spent on repetitive work. As a result, high amounts of financial resources and the faculty members' energy and time are wasted (5). Except for some specific cases, most thesis have become inconsequential for a variety of reasons, and the phenomenon of impractical dissertations has been threatening Iran's education system for years (10). There are different reasons why students' dissertations are impractical and not used to address the common problems of the society. These reasons include the weak link between the society and research, not choosing topics based on the real needs of the society, selecting topics based on the chance of being published or the time needed to complete the dissertations, selecting topics based on supervisors' interest or in line with the supervisor's previous research, lack of centralized policies regarding admission of students, and not establishing majors based on the needs of the society (11-14). In the study conducted by Kugnigk et al (2010), two critical components including interest in the topic and the accordance between the topic and future job choice, were mentioned as the reasons for choosing topics for dissertations (15).

Therefore, the accordance between the function of dissertations and needs assessment is a fundamental issue, and responding to problems and challenges in society is a serious concern of scientific institutions. Research indicates a myriad of challenges in choosing a topic for dissertations and a deep gap between the conducted studies and the real needs of the society. In this regard, directing medicine, dentistry, and pharmacy student's dissertations toward product-oriented researches can significantly affect the scientific and practical capabilities of students and improve their view of providing more effective services to society. This strategy creates concerns for the students regarding social responsibility and guides them toward social activities and social accountability. According to the discussions mentioned above, this study was conducted at Kerman University of Medical Sciences to extract alternative activities to diversify medicine, dentistry, and pharmacy student's thesis.

\section{Methods}

The present study was a descriptive cross-sectional study using the sequential exploratory design. It was conducted in the Education Development Center of Kerman University of Medical Sciences between February and June 2021. The qualitative phase was conducted to extract the alternative activities to 
medical, dentistry, and pharmacy student's thesis in three steps. In the first step the literature related to alternative activities for replacing dissertations, and criteria to evaluation them was reviewed. The search was performed in Medline, EMBASE, Web of Science, ERIC and Scopus from 2015 to 2020, and using the following key words: thesis, alternative, students, medical sciences, dentistry, pharmacy, and dissertation. In the second step, based on the extracted alternative activities and criteria for their evaluation, a checklist was designed to evaluate these criteria; two experts in medical education scored the activities in the checklist, and then the results were discussed. In the third step, twenty-two key informants of Kerman University of Medical Sciences were invited via email and, then invitations were confirmed in person. The informants were recruited based on the following criteria:

- Faculty members with the experience of educational affairs in schools of medicine, dentistry, and pharmacy.

- Faculty members active in supervising students in their thesis.

- Students from schools of medicine, dentistry, and pharmacy who had participated in activities of the Education Development Center.

The expert panel with the attendance of 20 key informants was held, and the results of the literature review, the evaluation checklist, and the suggested alternative activities were discussed by the experts. Their opinions on the alternative activities were collected using a pre-designed format at the end or after the session.

The quantitative phase of the study aimed to evaluate the extracted alternative activities for diversifying the medical, dentistry, and pharmacy student's thesis. In this phase, the extracted alternative activities were sent to the experts whose opinions were used in the qualitative phase, using an open-ended questionnaire.

The National Agency for Strategic Research in Medical Education approved the study, participants did not receive any incentives, and participation was voluntary. Verbal consent for participation was obtained based on the proposal approved by the ethics committee.

\section{Results}

In the first step of the qualitative phase, 31 alternative activities were extracted from the literature review. Moreover, the evaluation criteria including spending specific operational outcome, possibility of implementation, possibility of monitoring, research skill acquisition, lead to lifelong learning, and acquiring evidence-based decision-making skills were extracted for the evaluation of these activities. In the second step, after scoring the extracted alternative activities using the evaluation checklist, eight activities were excluded due to their low scores, and 23 activities reached the minimum required score. Based on the results of the expert panel in the third step, five alternative activities were excluded by the experts' opinions. These activities were then categorized into the five domains of individual development, research, education, healthcare, and social services. 
In the quantitative phase of the study, 15 of the 20 experts whom the extracted alternative activities list was sent gave their opinion on the activities. After receiving the opinions, some activities were corrected, and according to the results of the two phases, the alternative activities for diversifying the thesis of medical, dentistry, and pharmacy dissertations were finalized. Finally, 18 alternative activities in the five domains of individual development, research, education, healthcare, and social services were obtained. Table 1 presents the alternative activities for diversifying the thesis of medicine, dentistry, and pharmacy student's dissertations. 
Table 1

the alternative activities for diversifying the thesis of medicine, dentistry, and pharmacy student's dissertations

\section{Number Domain/Alternative activity}

\section{Individual development}

$1 \quad$ Participating in courses of clinical research methods, evidence-based medicine, medical education, health system management, and similar topics approved by the related college (minimum of 51 hours equal to 3 theoretical credits)

\section{Research}

$2 \quad$ Knowledge translation from systematic reviews published in accredited journals in specialized fields for healthcare and society (a minimum of 5 items)

3 Producing knowledge-based products, patent, software, and other technological activities

$4 \quad$ Composing case series for rare diseases and publish them in accredited journals (a minimum of two items)

$5 \quad$ Participating as a research assistant in $\mathrm{PhD}$ or residency student dissertations

$6 \quad$ Proposing and conducting a research plan in the student research committee and publishing article in the journals indexed in Scopus, PubMed, or ISI

$7 \quad$ Proposing and conducting a research plan in one of the research centers of the university as the main co-author

$8 \quad$ Conducting projects based on the product prototype and preparing a business plan, even based on existing studies, with complete consideration of the property rights

9

Conducting follow-up studies and medicine side-effects

10

Conducting group research projects with interdisciplinary topics

\section{Education}

11 Achieving a rank as the main or co-conductor of an educational process in the Shahid Motahari Festival

Achieving a rank as the conductor of a process in the Students' Innovative Ideas Festival

Achieving a medal (gold, silver, or bronze) in scientific Olympiads for medical students

\section{Healthcare}

14 Voluntary and extracurricular internship, in the form of presence in doctor's offices, clinics, and healthcare centers affiliated with university for at least three months

Voluntary and extracurricular internship in drugstores or pharmacology wards, affiliated with university for at least three months

\section{Social services}




\section{Number Domain/Alternative activity}

16 Internship in non-governmental organizations (NGOs), health charities, and science associations for at least three months, which must be done after the internship (e.g. working in epilepsy, diabetes, etc. associations)

17

Presence in and provision of voluntary services for three months in old people nursing centers (only after the internship) months with an acceptable operational report card

\section{Discussion}

In the present study, alternative activities for diversifying medical, dentistry, and pharmacy student's thesis were extracted and categorized into five domains of individual development, research, education, healthcare, and social services.

Research is considered as one of the bases of science, and a great number of researchers publish numerous studies in the form of dissertations and papers to solve problems in different areas and develop science each year (16). Dissertations not only play a crucial role in the production of new knowledge, but they are also considered as research practice for students and a way of producing new knowledge (17). Basically, dissertations represent the quality and status of education and research in universities. In this regard, much attention must be paid to their role in universities of medical sciences because these universities have a significant position regarding society's health status (18). It is expected that dissertations in medical sciences lead to the improvement and enhancement of public health (19).

Medical, dentistry, and pharmacy student's dissertations can be considered as useful research evidence in terms of their content as they try to identify problems and provide solutions. However, in many cases, these valuable research results find no practical use in society, and therefore, the mission of research, which is to utilize the findings, is not accomplished. As a result, trying to present practical dissertations for providing services to the society and meeting the needs of the public can have significant effects on increasing students' scientific and practical capabilities and providing better services to the society; moreover, it can make students socially responsible.

Generally, previous studies on this issue analyzed the dissertation results published as scientific papers. Caan et al (2012) stated that the analysis of doctoral clinical research publications of 39 universities between 2000 and 2010 revealed that $47.6 \%$ of the dissertations had not led to any significant publication.

The results of the study conducted by Hayatbakhsh Abbasi et al (2019) indicated that despite the high number of medical and PhD students' dissertations in Kerman University of Medical Sciences, few of them led to the production of scientific papers, and the number of articles indexed in international journals was insignificant. It was also mentioned that thesis writing is generally a unique opportunity for 
students to learn research skills and methods. In addition, publication of thesis findings in national and international databases can lead to scientific development (5).

However, we did not find any study analyzing the utilization of results of medical, dentistry, and pharmacy student's thesis in society and the practicality of these dissertations regarding social accountability. Kuhnigk et al (2010) investigated the reasons for discontinuing a medicine dissertation in five universities of medical sciences in Germany among 437 students. One of these reasons was the lack of association between the things students had studied in their thesis and the healthcare needs of the people (15).

In the present study, alternative activities for diversifying medical, dentistry, and pharmacy student's thesis were extracted and categorized into five domains of individual development, research, education, healthcare, and social services. Each category represents the effort to use students' thesis in line with social accountability.

One limitation of this study was the unwillingness of faculty members to participate in the expert panel due to heavy workload and lack of time. To overcome this limitation, we tried to explain the significance of this research in improving the quality and social accountability in dissertations.

\section{Conclusions}

The gap between what we know and what is seen in practice is plainly visible in medical, dentistry, and pharmacy student's thesis. According to research, it has always been recommended that knowledge be manifested in society; however, the presented study extracted activities to students' dissertations and directly turn them into practice in line with social service provision. Product-based dissertations can significantly affect students' scientific and practical capabilities and improve their view of providing more desirable services to society.

\section{Abbreviations}

Not applicable

\section{Declarations}

Acknowledgements: We thank the faculty members who participated in the expert panel for their support and involvement in the study.

Authors' contributions: MS, SN, and RM formulated the research idea. MS, SN reviewed the literature and facilitated the expert panel. MS, SN performed the analysis of the data and wrote the manuscript and edited the draft of the paper. All authors approved the final manuscript.

Funding: This study was funded by the National Agency for Strategic Research in Medical Education. Tehran. Iran. Grant No. 993889. The role of the funding body was in providing support for data collection 
and analysis.

Availability of data and materials: The datasets used and/or analyzed during the current study are available from the corresponding author on reasonable request.

Ethics approval and consent to participate: The Research Ethics Committees of National Agency for Strategic Research in Medical Education approved the study (No. IR.NASRME.REC.1400.038). Verbal informed consent was sufficient since the study had no intervention and its subject was not sensitive. Information on the study's aim and how expert's responses would be used was provided at the start of the expert panel to the participants. They were informed that their participation was voluntary, and anonymity was assured. When they agreed to participate, expert panel started. For documentation, whole process was audio recorded.

All methods were performed in accordance with the relevant guidelines and regulations.

Consent for publication: Not applicable.

Competing interests: The authors declare that they have no competing interests.

\section{References}

1. Haraldstad K, Wahl A, Andenæs R, Andersen JR, Andersen MH, Beisland E, Borge CR, Engebretsen E, Eisemann M, Halvorsrud L, Hanssen TA. A systematic review of quality of life research in medicine and health sciences. Quality of life Research. 2019 Oct;28(10):2641-50.

2. Veziari Y, Leach MJ, Kumar S. Barriers to the conduct and application of research in complementary and alternative medicine: a systematic review. BMC complementary and alternative medicine. 2017 Dec;17(1):1-4.

3. Biesta G. Why "what works" won't work: Evidence-based practice and the democratic deficit in educational research. Educational theory. 2007 Feb;57(1):1-22.

4. Gouda MA, Zidan HS, Marey AA, Gameal MG, Elmahrook RG, Saleh A, Nasr AA, Seifelnasr O, Radwan $A E$, Shahen A, Elgayar MM. Medical undergraduates' contributions to publication output of world's top universities in 2013. QJM: An International Journal of Medicine. 2016 Sep 1;109(9):605 - 11.

5. Karami Robati F, Alinaghi T, Hosseininasab A, Hayatbakhsh Abbasi MM. Study of the Status of Medical Students and Residents' Dissertation in Kerman University of Medical Sciences in Terms of Contribution to Scientific Development. Strides in Development of Medical Education. 2019 Dec $1 ; 16(1)$.

6. Nili MR, Nasr AM, Akbari N. Examination of the quality of guidance master's degree dissertations. Daneshvar behavior, 2007; 14(24): 111 - 22.

7. Baldwin MA, Rose P. Concept analysis as a dissertation methodology. Nurse Educ Today. 2009; 29(7): 780-3. 
8. Echeverria M, Stuart D, Blanke T. Medical dissertations and derivative articles: dissemination of contents and publication patterns. Scientometrics. 2015; 102(1): $559-86$.

9. Thamlikitkul V. Bridging the gap between knowledge and action for health: Case studies. Bull World Health Organ. 2006; 84(8): 603-7. 10.

10. Rezakhani Moghadam H, Shojaeizadeh D, Nabiolahi A, Moez S. The content analysis of dissertations in the field of health education in Tehran University of Medical Sciences, Tarbiat Modares University and Iran University of Medical Sciences during 1970-2010. J Payavard Salamat. 2011; 5(1): 80-90.

11. Rosenkranz SK, Wang S, Hu W. Motivating medical students to do research: a mixed methods study using Self-Determination Theory. BMC medical education. 2015 Dec;15(1):1-3.

12. Bhat S, d'Souza L, Fernandez J. Factors influencing the career choices of medical graduates. J Clin Diagn Res. 2012 Feb;6(1):61-4.

13. Giesler M, Boeker M, Fabry G, Biller S. Importance and benefits of the doctoral dissertation for medical graduates. GMS journal for medical education. 2016;33(1).

14. Marais DL, Kotlowitz J, Willems B, Barsdorf NW, Van Schalkwyk S. Perceived enablers and constraints of motivation to conduct undergraduate research in a Faculty of Medicine and Health Sciences: What role does choice play?. PloS one. 2019 Mar 13;14(3):e0212873.

15. Kuhnigk O, Böthern AM, Reimer J, Schäfer I, Biegler A, Jueptner M, Gelderblom M, Harendza S. Benefits and pitfalls of scientific research during undergraduate medical education. GMS Zeitschrift für medizinische Ausbildung. 2010;27(5).

16. Enteshari NF, Cheshmeh SM, Afshar E. The Use of Postgraduate Dissertations in Library and Information Sciences in Isfahan Libraries.

17. Alishri GH, Fakhre Jahani F, Rokhsarizadeh H, Miri SM, Hollisaz MT, Hosseini SM. [Evaluation of medical alumni dissertations of one of the medical sciences universities in principles of writing]. $J$ Mil Med. 2010;12(2):75-9.

18. Al-Busaidi IS, Al-Shaqsi SZ. Students' contribution to the New Zealand Medical Journal: a 14-year review. NZ Med J. 2015 Apr 17;128(1412):47-52.

19. Hanney SR, Gonzalez-Block MA, Buxton MJ, Kogan M. The utilization of health research in policymaking: concepts, examples and methods of assessment. Health research policy and systems. 2003 Dec;1(1):1-28.

20. Caan W, Cole M. How much doctoral research on clinical topics is published?. BMJ Evidence-Based Medicine. 2012 Jun 1;17(3):7 